\title{
Experimental and Numerical Investigation on the Influence of the Rate of Injection (Roi) on Engine Performance for B100 Fuel Control Strategy in Diesel Engines
}

\author{
Moïse Ligan Noukpo, ${ }^{1}$ Claude Valery Ngayihi Abbe $\mathbb{D}^{1},{ }^{1,2}$ Joseph Nkongho Anyi $\left(\mathbb{D},{ }^{2,3}\right.$ \\ Dieudonné Essola $\mathbb{D}^{1},{ }^{1,2}$ Cyrille Mezoue $\mathbb{D}^{1},{ }^{1,2}$ Ruben Mouangue $\mathbb{D}^{1,2}$ and Robert Nzengwa ${ }^{1,2}$ \\ ${ }^{1}$ National Higher Polytechnic School of Douala, Douala, Cameroon \\ ${ }^{2}$ Laboratory of Energy Material Modeling and Methods, University of Douala, Douala, Cameroon \\ ${ }^{3}$ Higher Technical Teachers' Training College Kumba, Kumba, Cameroon
}

Correspondence should be addressed to Claude Valery Ngayihi Abbe; ngayihiclaude@yahoo.fr

Received 5 September 2020; Revised 9 November 2020; Accepted 25 November 2020; Published 3 December 2020

Academic Editor: Zhong-Yong Yuan

Copyright (c) 2020 Moïse Ligan Noukpo et al. This is an open access article distributed under the Creative Commons Attribution License, which permits unrestricted use, distribution, and reproduction in any medium, provided the original work is properly cited.

\begin{abstract}
Maintaining the quality of breathing air in urban and industrial areas is one of the biggest challenges faced by humanity in the modern era. Diesel engines, as one of the main providers of energy supply for modern equipment and transport, are also unfortunately contributing highly to the deterioration of air quality. A recent research path on the limitation of diesel engine emissions is the use of alternative fuel from vegetable or animal fats or oil called biodiesel. Although the use of biodiesel has proven its efficiency in reducing emissions, it remains a problem to maintain the engine's efficiency when shifting to biodiesel, especially due to its injection and atomization properties; most of the recent research focused on improving biodiesel fuel quality by blending it with traditional diesel fuel, but few works can be found on the regulation or control of diesel engine process when shifting to $100 \%$ biodiesel fuel (B100). This work proposes a fuel control strategy and methodology based on diesel engine operating data obtained from an experimentally designed rate of injection model (ROI) at different injection pressures and a jet and spray droplet distribution validated a two-zone model. Results show that B100 gives a higher amount of about $8 \%$ of injected fuel, a longer jet penetration of about $20 \mathrm{~mm}$ higher at $100 \mathrm{MPa}$ injection pressure, a wider cone angle, and about a $40 \%$ increase of coarseness of the jet distribution. The experimental and numerical-based control strategy provides interacting relationships between B100 properties and specific engine features where actions shall be made to keep the engine's efficiency when the shift is made; meanwhile, the algorithm provides a hierarchical step-by-step correcting procedure taking into account the possible degradation that could occur from the use of B100 in diesel engines.
\end{abstract}

\section{Introduction}

The use of alternative fuels such as biodiesel is nowadays the center of interest of multiple research groups and engine manufacturers in the automotive industry [1-4]. Biodiesel is a renewable energy source from vegetable or animal oils; as a methyl ester, it is an environmentally friendly alternative to hydrocarbon liquid fuels such as diesel [5-7] that can be used in any diesel engine without change [2]. However, it was noticed that when converting diesel engines to function on biodiesel fuel, there happens to appear significant changes in the qualitative and quantitative nature of the engine working process. These changes were noticed at the economic, technical, and environmental levels $[2,3]$, especially on the use of $100 \%$ biodiesel fuel (B100). The main influence of biodiesel characteristics on engine power was mainly observed on the rate of injection, torque, and cyclic fuel supply. Most of the time, the problem that arises is the question of ensuring the preservation of the operational characteristics of the diesel engine when it is converted to biodiesel. Most of the shifts performed consist of using a blend of diesel and biodiesel fuel to attenuate the penalizing 
effects resulting from the use of pure biodiesel. The liquid fuel flow characteristic is one of the main parameters to be taken into account for the design and optimization of a diesel engine [8-10]. In this regard, the cold flow properties of B100 fuel have been a major concern for its use as its pour point is quite higher than that of conventional diesel fuel. This often leads to problems for fuel supply to the injector in particularly cold weather as well as the starting of engines when cold [11]. Filter plugging problems caused by biodiesel components such as bysterol glycosides and saturated monoacylglycerols are also a discouraging aspect of the use of B100 in diesel engines [12]. Maintaining the performance of a diesel engine within acceptable limits when converting it to biodiesel cannot be done without improving the method of fuel supply and stability control, which will automatically correct defects in the engine when it is converted to biodiesel. When designing a diesel fuel system, special attention is paid to the configuration of the injectors, namely, the diameter and number of holes of the nozzle holes of the injector. A good number of diesel engine operating models describing the process of fuel injection in diesel engines take into account most of the abovementioned parameters.

Razleytsev and Lyshevsky's models [13, 14] give relationships permitting the definition of the spray fineness, droplet distribution, and dynamics of combustion taking into account the diameter and number of holes of the injectors. The model of [15] gives an approximation of the fineness of the spray cloud (average diameter of the atomized fuel droplets) of the fuel taking into account the diameter of the nozzle hole as well. Hiroyasu [16-18] model, which is widely used, presents the fuel jet as a liquid overcoming a primary and secondary breakup where the fuel droplets progressively split as packets from the main liquid jet; its main limitation is that it hardly defines the subsequent dynamic of combustion occurring after injection. Some other models are also used, especially multidimensional, such as the Kelvin-Helmholtz, Rayleigh-Taylor [19, 20], and Reitz-Diwakar [21], for secondary breakup models, provide fairly accurate results compared to experimental data but their implementation needs a high computational cost. It should be noted that no calculation model is absolute and the model can only be used conditionally to assess the quality of the spray depending on the objectives (engine design or control). To describe the process of injection and spray, it is not essential how accurately the absolute value of the average droplet diameter can be determined by the approximate criterion equation, but mostly to be able to assess the relative change in the quality of fuel spray with variable injection conditions. To ensure rapid and complete combustion in diesel engines when converting to biodiesel fuel, one must find a way to intensify the process of evaporation and mixing, i.e., increase the contact surface of biodiesel droplets $[22,23]$ with masses of hot air. It is known that for the conventional diesel fuel, one of the ways to increase the rate of evaporation and mixture formation is to increase the fineness of fuel spray, which is characterized by small droplets and uniform distribution in the combustion chamber due to increased injection pressure.
In [24], the influence of such factors as injection pressure, nozzle diameter, fuel viscosity, and the density of the environment on the fuel spray, is considered. In [12], the influence of different factors on the fineness of the spray, such as injection pressure, fuel viscosity, the density of the environment, and vorticity of fuel in the nozzle channel, is given. For example, it is noted that with increasing injection pressure, the spray quality improves, and with increasing fuel viscosity, the spray becomes coarser [25]. In [15], calculation formulas are given that relate in detail the injection pressure, the cross-section of the nozzle holes, the fuel viscosity coefficient, and other parameters. However, these dependencies sometimes do not allow the assessment of the quality of the spray (neither fineness nor homogeneity and uniformity) and do not take into account the geometry of the flowing part of the spray body. A fairly detailed model for calculating the spectrum of droplet size is presented in [26].

This work gives a contribution to the determination of the nature of changes in the quality of spray characteristics depending on the injection pressure and type of fuel. It will lead to the proposal of methods for the control chart of fuel supply when converting diesel engines to B100 fuel in a way to maintain qualitative indicators of spray, fuel injection, and combustion. It is then proposed to analyze the influence of physicochemical properties of B100 fuel on the parameters of the fuel supply system and, on this basis, to develop the basics of a methodology of fuel supply control when converting diesel engines to operate on B100 fuel.

The methodology is as follows:

(i) Determining the parameters of the fuel supply system affecting the performance of the diesel process employing numerical simulation based on experimental data

(ii) Determining the impact of the fuel supply system's factors and fuel type on the performance of the diesel process

(iii) Determining the necessary actions to eliminate or compensate in the diesel process when the conversion to full B100 fuel is performed

(iv) Proposing a regulatory algorithm for diesel engine performance when converted to operate on B100 fuel

\section{Materials and Methods}

2.1. Rate of Injection Generation and Variation. To generate the rate of injection, a virtual injection rate generator from the engine combustion network was used (spray B) [27, 28]. The virtual injection rate generator was designed using the methodology described in [29-32], where the ROI of the rail is recorded by a pressure transducer in an anechoic volume filled with the injected fuel; this method is called the Bosch method [29]. A gravimetric balance is used to adjust the ROI signal and permits the evaluation of the amount of injected fuel. A rate meter records time-resolved mass flow rate. It has been shown that, with a good calibration, these types of equipment provide a standard deviation at around $0.6 \%$ for 
these tests [33]. To eliminate the cumulative phenomenon, which is usually due to high-speed injection and brings up a clear difference between the recorded signal and the actual mass flow rate of the injected fuel at the stabilized period of the injection, a correction methodology is applied [29]. The methodology is based on numerical solutions and iterative techniques. It is assumed that the measured signal " $z$ " can be given as the sum of the real injection rate signal " $z$ " and the cumulative phenomenon signal; the problem is then described as a first-order linear system where it responds to an input signal $y$ and yields the function $r$ which is the cumulative signal:

$$
\frac{\mathrm{d}_{r}}{\mathrm{~d}_{t}}+\omega r=K y .
$$

The problem is solved when $y$ is found knowing $z$ and after determining the constants $\omega$ and $K$.

The specifications of the spray $B$ are given in Table 1 . The spray B geometric configuration can be seen in Figure 1; it is the spray produced from the hole drilled opposite to the fuel tube. The figure presents the orientation of the hole about the axis of the fuel tube. The injection pressures were varied from 50 to $150 \mathrm{MPa}$ with a step of $50 \mathrm{MPa}$ for each fuel. The duration of Injection was taken equal to $1.50 \mathrm{~ms}$.

2.2. Investigated Engine and Fuel. For the sake of investigation and providing the characteristics needed for diesel and biodiesel fuel operation, a one-cylinder HSDI diesel engine was used for the numerical model validation [34]. The initial benchmark for our validation was a configuration in which dwell time between split injections was taken equal to zero $[35,36]$. The engine parameters can be found in Table 2 and the engine operating mode in Table 2. Other aspects concerning the experimental setup for the given benchmark can be found in [35]. The investigated parameters were taken at a rated speed of $1500 \mathrm{rpm}$, see Table 3 .

Diesel fuel and biodiesel fuel surrogates were taken to be used in the engine operations; namely, methyl butanoate [37] for biodiesel and a blend of hexadecane and isocetane for diesel fuel.

2.3. Mathematical Modeling. The model used in our study combines a multizone injection and spray model $[13,37]$ and a $0 \mathrm{D}$ thermodynamic model. A step-by-step chart of the model algorithm is provided in Figure 2.

The spray model is based on Razlejtsev and Kuleshov $[13,38]$ model for in-cylinder spray distribution and evaporation during diesel engine operation. The experimental rate of injection (ROI) has been adapted for the model to acquire the cyclic supply of fuel per cycle $q_{c}$ in $\mathrm{Kg} /$ cycle, with

$$
q_{c}=\int_{\mathrm{SOI}}^{\mathrm{EOI}} q_{i} \cdot \mathrm{d} t
$$

where SOI is the start of injection $(s)$, EOI is the end of injection, and $q_{i}$ is the $\mathrm{i}^{\text {th }}$ mass of fuel injected at time $t_{i}$.

The liquid length is computed as follows:

$$
\begin{aligned}
L_{b} & =C_{s} d_{n} W_{e}^{0.25} M^{0.4} \rho_{l}^{-0.6}, \\
t_{b} & =\frac{l_{b}^{2}}{B_{s}},
\end{aligned}
$$

where $C_{s}$ is a weighting coefficient, $d_{n}$ is the diameter of the injector nozzle, $W_{e}$ is the Weber number which depends on the initial speed of the jet, $M$ is a dimensionless criterion [13] characterizing the ratio between the surface tension force and viscosity, and $\rho_{l}$ is the density of the fuel.

The Weber number is calculated according to the following relation:

$$
W_{e}=\frac{U_{0}^{2} \rho_{f} d_{c}}{\sigma_{f}},
$$

where $U_{0}$ is the initial speed of the fuel jet which is expressed by

$$
U_{0}=\frac{24 q_{c} \mathrm{RPM}}{0.75 \rho_{f} \pi d_{c}^{2} i_{c} \varphi_{\text {inj }}}
$$

where RPM is the rotation speed of the crankshaft in $\mathrm{rev} / \mathrm{min}$, $\rho_{f}$ is the density of the fuel in $\mathrm{kg} / \mathrm{m}^{3}$, dc is the diameter of the injector holes in $\mathrm{mm}$, and $\varphi_{i n j}$ is the duration of the injection given in the degree of rotation of the crankshaft. Criterion $M$ is calculated by

$$
M=\frac{\mu_{f}}{\left(d_{c} \rho_{f} \sigma_{f}\right)}
$$

with $\mu_{f}$ being the dynamic viscosity of the fuel at $323 \mathrm{~K}$ in $\mathrm{Pa} \cdot s$ and $\sigma \mathrm{f}$ being the surface tension coefficient of the fuel at $323 \mathrm{~K}$ in $\mathrm{N} / \mathrm{m}$.

The length of the liquid jet is then calculated for each phase according to the following formulas:

For $0<t<t_{b}$,

$$
S=A_{S} \ni^{0.35} \exp -0.2 \cdot\left(\frac{t}{t_{b}}\right) .
$$

For $t>t_{b}$

$$
S=B_{S}^{2} t^{0.5} .
$$

where $A_{S}$ is an empirical constant and $\ni$ is a criterion used to characterize nonstationary processes.

The variation of the cone angle of the jet as a function of time is given as follows:

For $0<t<t_{b}$,

$$
\theta=2 \arctan \left[\begin{array}{c}
E_{S} W_{e}^{0.35} M^{-0.07} \\
\cdot \ni^{-0.12} \rho_{l}^{0.5} e^{0.07\left(t / t_{b}\right)}
\end{array}\right] .
$$

For $t>t_{b}$

$$
\theta=2 \arctan \left[\begin{array}{c}
F_{S} W_{e}^{0.32} M^{-0.07} \\
\cdot \ni^{-0.12} \rho_{l}^{0.5}
\end{array}\right],
$$

with $E_{S}=0.932 F_{S} W_{e}^{0.32} \ni^{-0.12}$ and $F_{S}$ being the empirical constants. 
TABle 1: Spray B specified nozzle geometry $[27,28]$.

Specifications for spray B injectors of the engine combustion network

Common rail fuel injector

Fuel injector nominal nozzle outlet diameter

Nozzle $K$ factor

Nozzle shaping

Mini-sac volume

Discharge coefficient at $10 \mathrm{MPa}$ pressure drop

Number of holes

Hole angular position

Orifice orientation relative to injector axis
Bosch solenoid-activated, generation 2.4

$0.090 \mathrm{~mm}$

$K=\left(\mathrm{d}_{\text {inlet }}-\mathrm{d}_{\text {outlet }}\right) / 10$ [use $\left.\mu \mathrm{m}\right]=1.5$

Smoothed by hydroerosion

$0.2 \mathrm{~mm}^{3}$

$C_{\mathrm{d}}=0.86$ (room temperature using diesel fuel)$$
\theta=36.4^{\circ},-62.3^{\circ} \text {, and } 180^{\circ}
$$

$\psi=72.5^{\circ}\left(145^{\circ}\right.$ full-included angle)

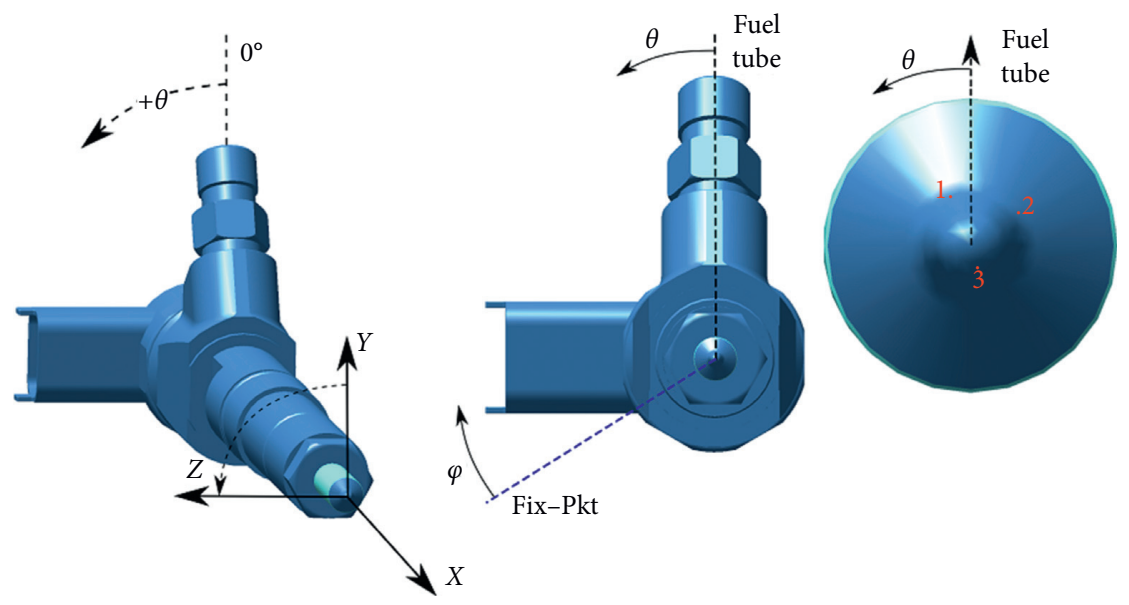

Figure 1: Spray B geometry.

TABLE 2: Engine geometry and fuel properties.

\begin{tabular}{lcc}
\hline Items & Units & Values \\
\hline Engine geometry & - & 4 \\
Valves & $\mathrm{mm}$ & 82 \\
Bore & $\mathrm{mm}$ & 90.4 \\
Stroke & $\mathrm{L}$ & 0.477 \\
Displacement volume & - & 16.69 \\
Compression ratio & & \\
\hline Fuel Biodiesel surrogate & & \\
$\mathrm{C}_{5} \mathrm{H}_{10} \mathrm{O}_{2}$ & & \\
\hline Fuel Diesel surrogate & & \\
$42 \% \mathrm{n}-\mathrm{C}_{16} \mathrm{H}_{34}$ & iso- $\mathrm{C}_{16} \mathrm{H}_{34}$ \\
\hline
\end{tabular}

TABLE 3: Engine operating parameters.

\begin{tabular}{lcc}
\hline Items & Units & Values \\
\hline Engine speed & $\mathrm{Rpm}$ & 1500 \\
Swirl ratio (Ricardo) & - & 2.2 \\
IMEPg & $\mathrm{Bar}$ & $9.0+-0.1$ \\
Injection pressure & $\mathrm{Bar}$ & 800 \\
$\mathrm{~m}_{\text {pilot }}$ & $\mathrm{mg} / \mathrm{str}$ & 1.5 \\
Dwell time, $\delta \mathrm{t}$ & $\mathrm{Ms}$ & $0,90,140,300$ \\
Intake temperature & $K$ & 347.15 \\
Top dead center (TDC) temperature & $K$ & 925 \\
TDC density & $\mathrm{kg} / \mathrm{m}^{3}$ & 21.8 \\
Exhaust gas recirculation (EGR) & $\%$ & 10.3 (includes $3.3 \%$ residual fraction) \\
MFB50 (50\% burnt fuel crank angle) & Crank angle degree after & $13+-0.5$ \\
\hline
\end{tabular}




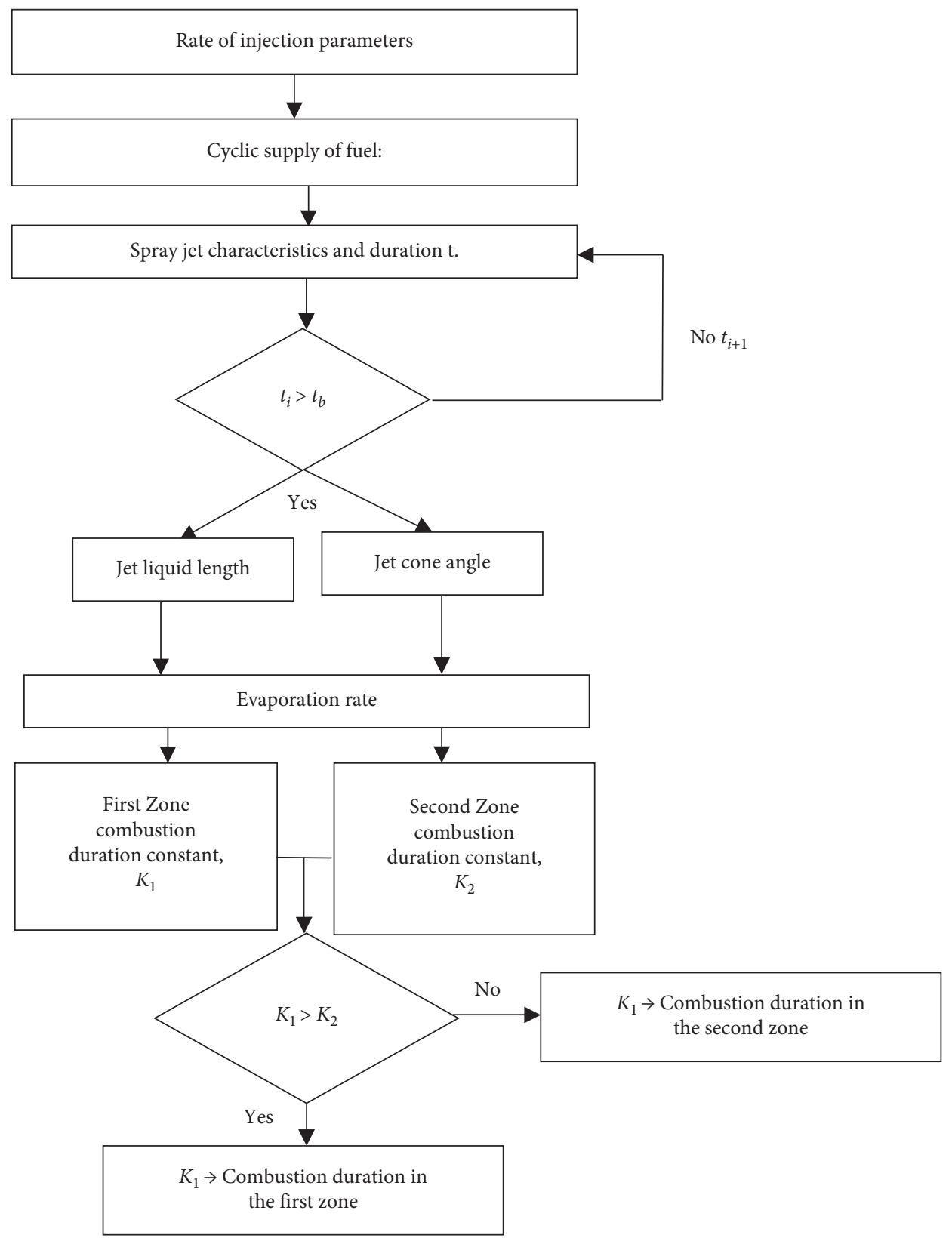

FIgURE 2: Model flow chart for the determination of combustion kinetics.

2.4. Evaporation Submodel. The injected fuel disperses into fine particles after passing through the transition zone; these fine droplets undergo evaporation at a given speed. Razlejtsev $[13,14]$ suggested the following procedure for determining the rate of evaporation of droplets from the injection of fuel for a diesel engine. Razlejtsev [13, 14] proposed the description of the vapor of the fuel jet in two zones: the first zone is where the inhibited droplets are concentrated in the form of a cloud behind the flame front surface; the second zone is where the droplets have reached the flame front and where the evaporation has a turbulent character.

The purpose of the calculation in this submodel is the determination of the parameters of the fineness of the pulverized fuel as well as that of the distribution of the droplets in the jet fuel vapor. These parameters will subsequently be used to calculate the average rate of evaporation of the sprayed droplets and therefore the duration of combustion for a cycle.

The fineness of the spray is determined using the Sauter diameter, which is calculated for each zone according to the following formula:

$$
d_{32}=1.7 d_{n} M^{0.0733}\left(W_{e} \cdot \rho\right)^{-0.266},
$$

where $\rho=\left(\rho_{a} / \rho_{l}\right)$ is the density ratio between dry air and liquid fuel. The evaporation of droplets follows the $d_{2}$ law [15], for which the evolution of a droplet in full evaporation over time is given by 


$$
d_{i}^{2}=d_{0}^{2}-K \cdot t
$$

with $d_{0}$ being taken as the diameter of the droplet after the jet dispersion into fine droplets according to equation (11) and $d_{i}$ being the diameter of the droplets at the instant of observation and $K$ is the evaporation constant of the area which is given by

$$
K=\frac{10^{6} \cdot 4 N_{u} D_{p} p_{s}}{\rho_{l}},
$$

with $\mathrm{Nu}$ being the Nusselt number for the diffusion processes and $D_{p}$ being the diffusion coefficient for the fuel vapor and $p_{s}$ being the saturated vapor pressure of the fuel.

It is necessary to characterize the Nusselt number and therefore the evaporation constant in the two zones of the fuel vapor. The saturation vapor pressure is calculated according to the following formula as a function of the vapor temperature $T_{f}$ :

$$
p_{s}=A \cdot e^{-\left(B / T_{f}\right)}
$$

The coefficients $A$ and $B$ are determined according to two points $[10,14]$, for $p_{s}=p_{\text {atm }}$ with $T_{f}=T_{\text {boil }}$ and for $p_{s}=p_{c r}$ with $T_{f}=T_{c r}$.

The fuel vapor diffusion coefficient can be calculated as a function of temperature and pressure according to the following formula:

$$
D_{p}=D_{p 0}\left(\frac{T_{f}}{T_{\mathrm{atm}}}\right)^{m}\left(\frac{p_{\mathrm{atm}}}{p}\right)^{n},
$$

with $D_{p 0}=0.031 \cdot 10^{-8}$, which is the diffusion coefficient of diesel-type fuels for conditions such as $T_{\text {atm }}=273 \mathrm{~K}, p_{\mathrm{atm}}=0.1 \mathrm{MPa}$. The coefficients $m$ and $n$ are taken equal to unity.

Nusselt's number and temperature $T_{f}$ also vary depending on fuel evaporation conditions and nonstationary processes. For the first zone, the droplets evaporate mainly under the conditions of thermal transfer of conduction and molecular diffusion, and the Nusselt number can thus be taken equal to 2 . The temperature of the vapor is of the order of $T_{f}=(0.95 \ldots 0.98) T_{c r}$.

For the second zone, due to the turbulent nature of the jet fuel vapor, the Nusselt number is calculated according to the following formula:

$$
N_{u}=2\left(1+0.3 R e^{(1 / 2)} S c^{(1 / 3)}\right) \text {, }
$$

where Re expresses the Reynolds number and Sc the Schmidt number. The steam temperature is calculated for this zone by

$$
T_{f}=\left(\frac{\left(T_{c}+T_{c r}\right)}{2}\right),
$$

with $T_{c}$ being the temperature of the chamber at the end of compression before TDC.

It is thus possible to compute the evaporation constant for each zone of the fuel vapor. The study of the kinetics of combustion requires us to use the highest value of this constant in the two zones to evaluate the relative duration of complete evaporation of the fuel jet in the combustion chamber.

Let $K=\max \left(K_{1}, K_{2}\right)$, with $K_{1} K_{2}$ being the evaporation constants for each of the zones.

The relative combustion time for the cycle is calculated in seconds according to the following relationship:

$$
\tau_{e v}=\left(\frac{A_{z}}{\left(b_{i t} \lambda^{0.6}\right)}\right),
$$

with $b_{i t}=\left(K / d_{32}\right)$ which is the relative evaporation constant of the droplets.

The $A_{z}$ coefficient is an empirical weighting coefficient used to adjust the pressure curve relative to the experiment, and its value varies from 4 to 12 [38].

The duration of combustion of the cycle is finally converted into the degree of rotation of the crankshaft according to the following formula:

$$
\varphi_{z}=\varphi_{\text {inj }}-I D+6 \cdot \mathrm{RPM} \cdot \tau_{e v},
$$

where $\varphi_{z}$ is the combustion duration, $\varphi_{\text {inj }}$ is the start of injection angle, and ID is the ignition delay.

\section{Results and Discussion}

3.1. Experimental and Simulation Results. The ROI of the different fuels at different pressures were generated (Figure 3) and it can be seen that biodiesel will generate a higher amount of about $8 \%$ of fuel injected per cycle as compared to conventional diesel fuel. This has been observed in previous studies and is explained by the differential in viscosity of the two fuels $[39,40]$ and higher viscosity of biodiesel usually resulting in loss of flow efficiency, thus generating a higher quantity of injected fuel. This generally leads to higher fuel consumption when the shift to biodiesel is performed.

Figures 4 and 5 present the fuel jet velocity and jet penetration for both fuels at a pressure of $100 \mathrm{MPa}$; it can be observed that the model predicts similar values for both fuels. The fuel jet comes out from the nozzle at approximately $500 \mathrm{~m} / \mathrm{s}$ and decreases with time until about $40 \mathrm{~m} / \mathrm{s}$ for a penetration of about $75 \mathrm{~mm}$ at $12 \mathrm{CAD}$; the biodiesel fuel exit speed decreases faster than that of the diesel fuel and reaches about $20 \mathrm{~m} / \mathrm{s}$ for a penetration of about $98 \mathrm{~mm}$ at 12 CAD. This trend can be observed for each pressure and can be explained by the higher viscosity of biodiesel that would lead to higher losses in the fuel nozzle. This result is in accordance with findings in the previous literature [41] where it is found that the rheological properties of biodiesel generate more losses in the fuel lines that would lead to poor atomization and generate higher quantities of unburned liquid fuel.

Figure 6 presents a comparison of fuel cone jets for different fuels at the three designed injection pressures; the jet penetration and cone angle of each fuel at each injection pressure can be seen. What comes out at first sight from the graphics is that the liquid jet length is higher for biodiesel at every injection pressure. As stated above, the main explanation for this comes from the higher viscosity of biodiesel, 


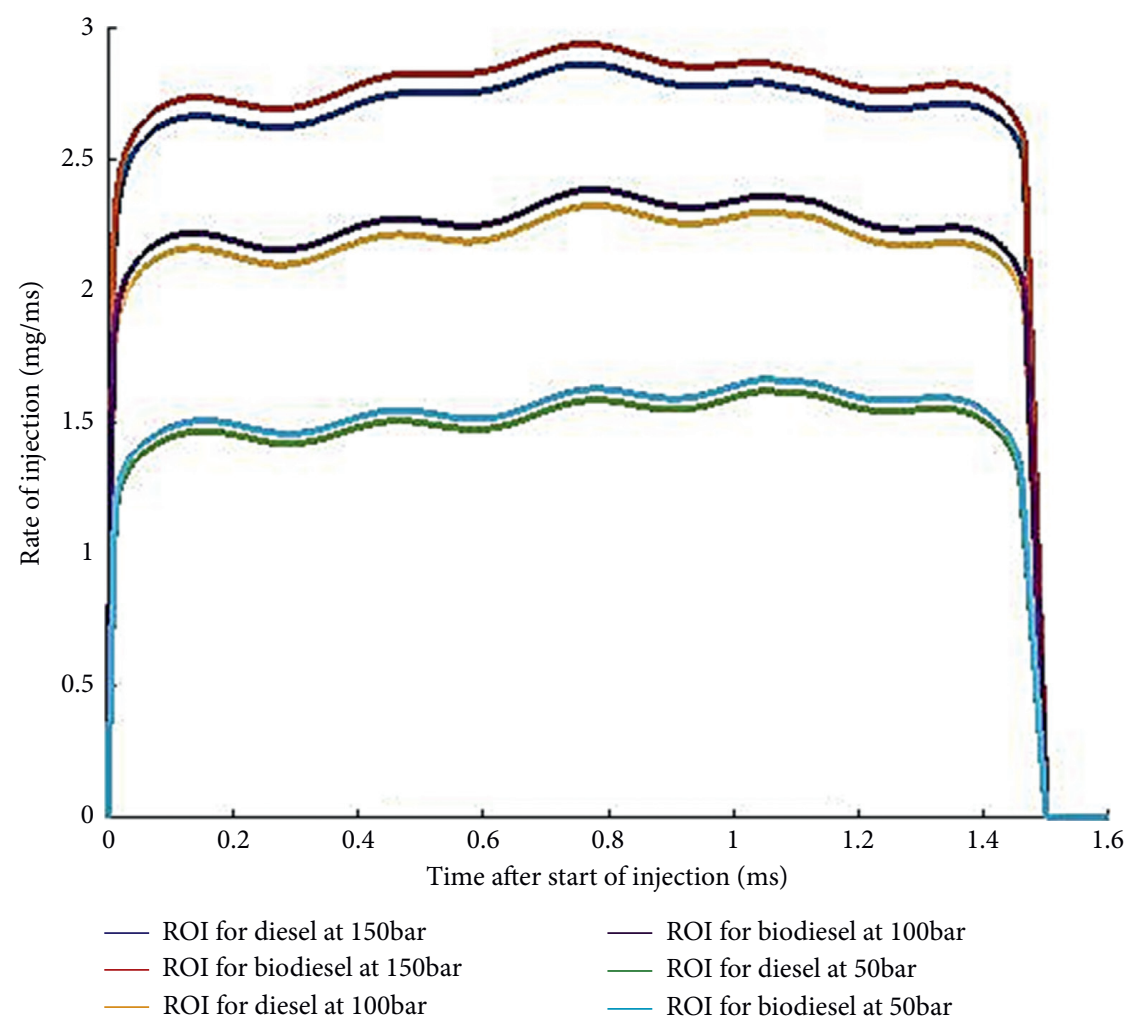

Figure 3: Rate of injection at different pressure.

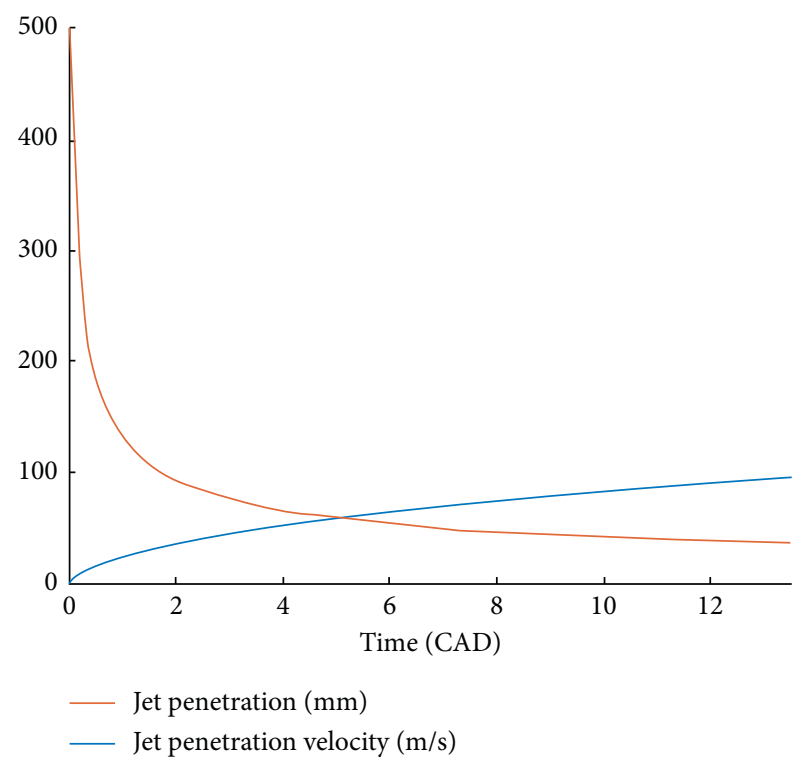

FIGURE 4: Jet penetration and velocity of diesel at $100 \mathrm{MPa}$.

but fuel density and surface tension can also affect the trend observed [25,42]. Also, the spray cone angle is higher for the biodiesel compared to the diesel fuel; the model predicts that this trend has been observed in experimental and numerical studies [41, 42]. Biodiesel fuel, higher jet angle, and penetration would then lead to higher wall impingement and smoke due to poor combustion. However, this result contradicts the experimental finding of [33] where a slightly

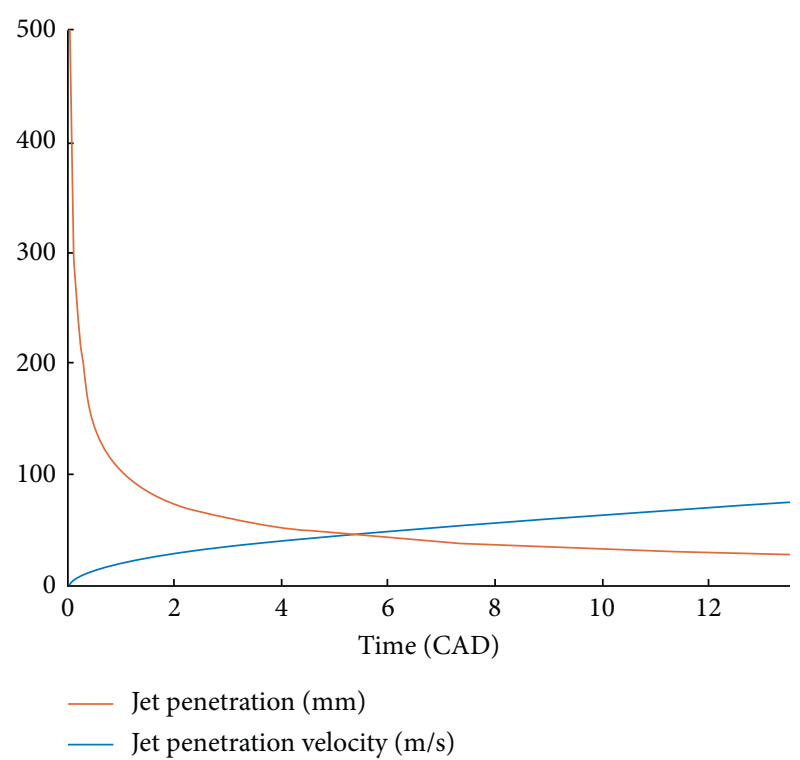

Figure 5: Jet penetration and velocity of biodiesel at $100 \mathrm{MPa}$.

higher cone angle for biodiesel is found; it is important to note that our simulation is concerning a $100 \%$ biodiesel fuel, whereas in [33], it was a blend of $30 \%$ biodiesel; the experimental setup, conditions, and measurement uncertainties can also explain the contradictory results.

Figure 7 shows the comparison of the Sauter mean diameter and combustion duration at different combustion zones for various injection pressures for both diesel and 

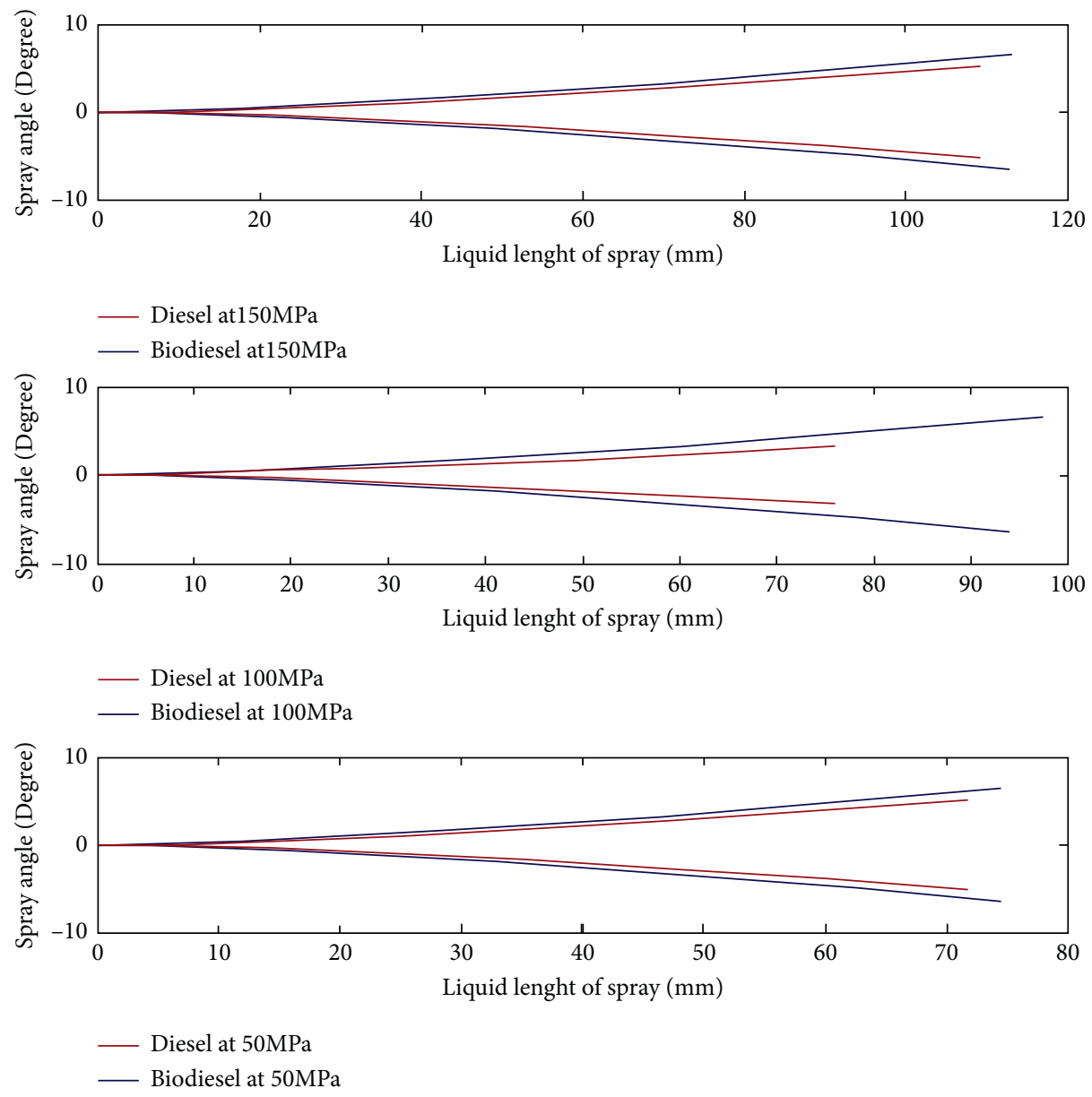

FIgURE 6: Comparison of fuel jets at various injection pressures.

B100 fuel. As expected, the SMD (Sauter mean diameter) for the biodiesel is higher (about $40 \%$ higher) than that of gasoil; it eventually leads to a longer combustion duration. A longer combustion duration means a modification in the cycle parameters initially designed. What is also interesting to see is that with increased pressure, biodiesel SMD and combustion duration tend to reduce; this has been observed experimentally by $[43,44]$ and is captured by our model.

As a whole, the main observation that can be made is that conversion to biodiesel fuel for diesel engines leads to coarser atomization of the injected fuel, mainly due to the rheological parameters of the biodiesel. The two-zone model used, which was based on experimental ROI parameters, captures well these trends and proves its good capability of prediction. From the observations made, a strategy of control procedure and monitoring can then be proposed; this is followed in the next section.

3.2. Control Methodology and Algorithm Proposal. Based on the theoretical description of the process of evaporation and combustion, it is possible to develop a method for control and monitoring the supply of fuel in diesel. We propose a block diagram (Figure 8), which describes the various structural relationships between the underlying parameters in the process of fuel injection and combustion. The scheme consists of various components: controlled processes, internal parameters of external parameters, output parameters, and output. Controlled processes are those in which values are the result of a combination of input parameters, internal and external parameters, and which define and strictly characterize the working process of the diesel engine. Internal process parameters are parameters directly related to the construction or operation of the diesel engine. The input parameters are known parameters, i.e., parameters in which values cannot be changed; it can be information about the fuel or the design of the engine. The output parameters are parameters characterizing the working process of the diesel engine. They directly depend on the interaction between input parameters, internal and external parameters. The relationships between the various parameters of the circuit can be described as follows.

The processes of evaporation and combustion in a diesel engine begin with the injection of fuel into the combustion chamber, followed by the atomization of the fuel. This part occurs before the evaporation process and is characterized by the finesses of the sprayed fuel jet, its range, and homogeneity. The parameters that are directly related to the process of fuel injection and spray are physical parameters of the fuel, such as viscosity, density, and surface tension 

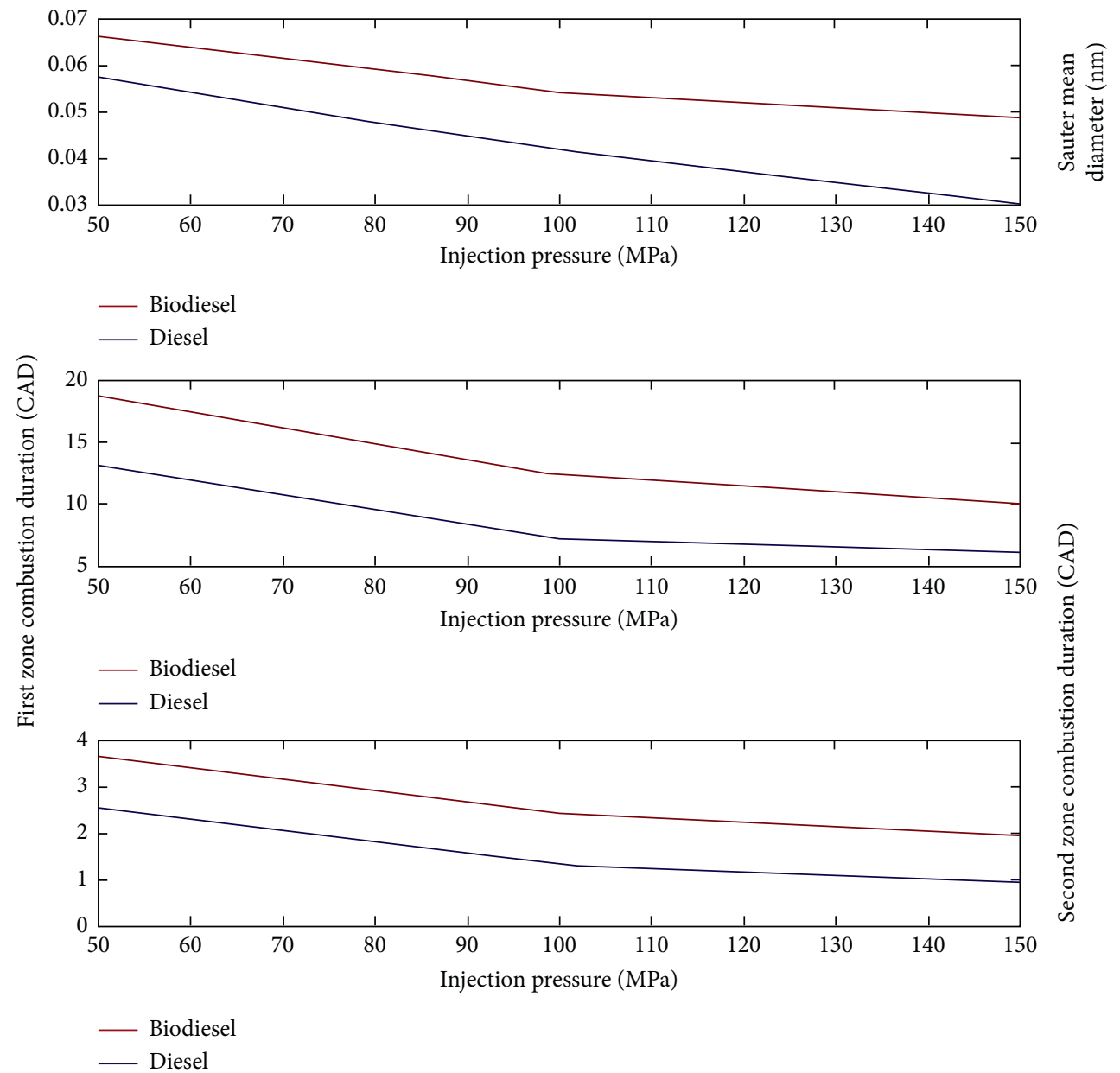

FIgURE 7: Comparison of Sauter mean diameter and combustion duration at various zones for various injection pressures.

coefficient. The injection and spray processes also depend on the fuel supply system, such as the nozzle diameter of the hole, the injection pressure, the start of injection angle, the number of holes of the injectors, and the injection period. Another parameter that can be added to the fuel supply system, especially concerning the efficient fuel storage in the tank, is the oxidation stability of B100 fuel $[45,46]$. Changing or modifying the above parameters leads to a change in the characteristics of the injection and spray process. The scheme shows that the evaporation step is a direct result of the processes of injection and spraying. The diagram shows that evaporation has a direct relationship with fuel density.

After the stages of injection, spray, and evaporation of fuel, the block diagram describes the process of ignition delay of the fuel. Unlike the previous stage, it depends not only on its previous stage but also on the chemical parameters of the fuel, such as cetane number and activation energy. The block diagram also describes that the ignition delay depends on the fuel injection system, especially on the injection angle and the configuration of the cylinder-piston group, which determines the temperature and gas pressure at the time of injection.
The last element of the process is the duration of the combustion process, which has a direct impact on the efficiency of the parameters of the diesel process. This step consists of the sum of the previous steps but does not fully determine the efficiency of the engine workflow. Although the characteristics obtained at this stage are crucial, we know that the efficiency of diesel engines directly depends on the physical properties of the fuel, such as the heat of combustion, which determines the power and fuel consumption. The duration of combustion is a determining factor for the value of pressure and temperature in the cylinder during the working process. Thus, the presented control scheme has the advantage that it describes the combustion process as a network of specific information transmission. There are clear links between fuel and the various stages that make up the process of injection and combustion in diesel engines. Thus, it is possible, with different fuel data, to determine exactly how they will affect the combustion process, as well as to easily determine which components shall be identified to correct any malfunctions or inconsistencies that occur during the use of any fuel. The functional diagram shows the relationship between the parameters of the diesel system and the 


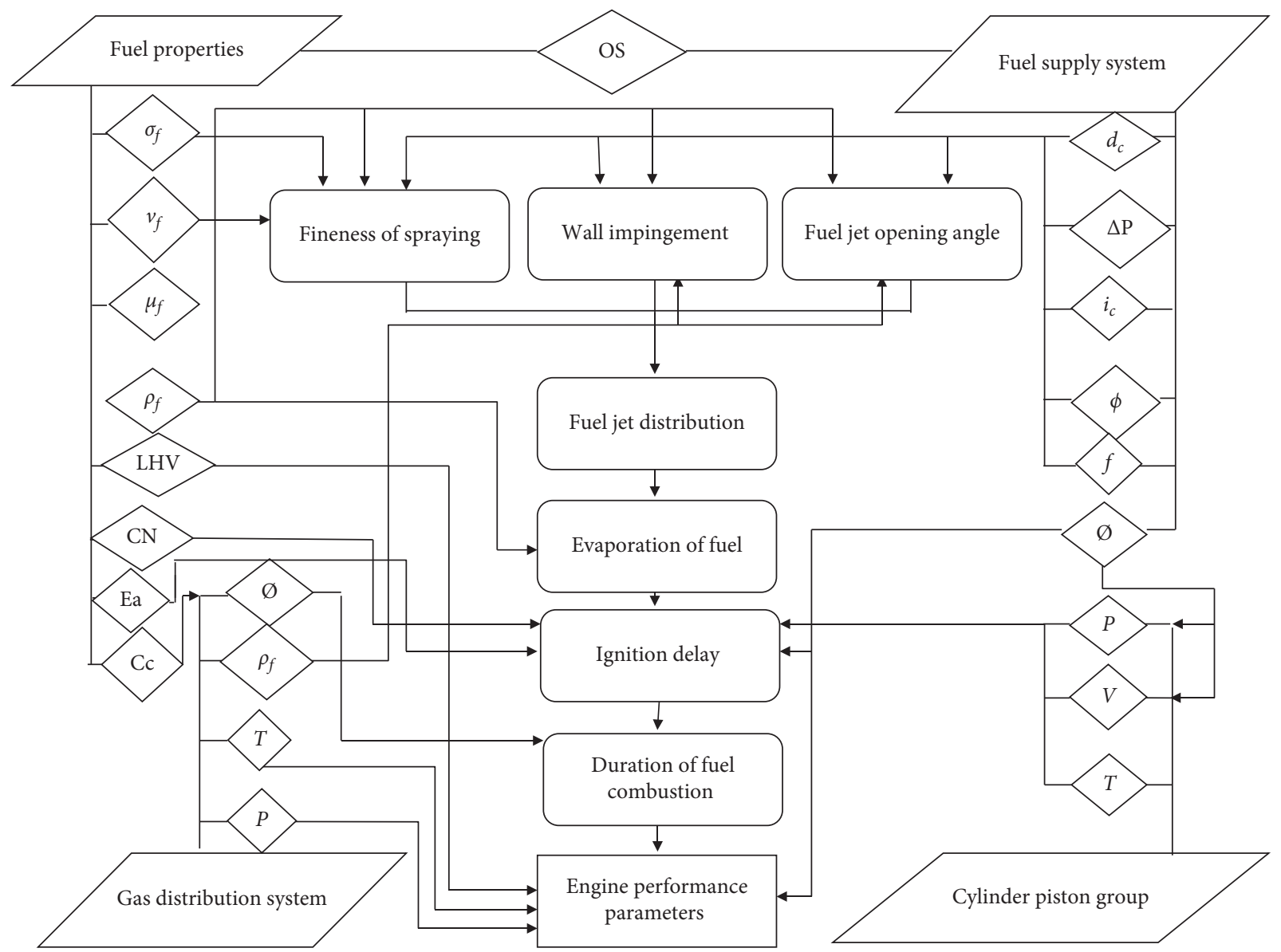

FIGURE 8: Block diagram of the fuel supply control. $\sigma_{f}$ fuel dynamic viscosity; $v_{f}$ fuel kinematic viscosity; $\mu_{f}$, fuel surface tension coefficient; $\varnothing$, equivalence ratio; $\rho_{f}$, fuel density; $E_{a}$, activation energy; $L H V$, fuel lower heating value; $C N$, fuel cetane number; $\Delta P$, injector pressure differential; $\mathrm{T}$, in-cylinder temperature; $\mathrm{P}$, in-cylinder pressure; $V$, in-cylinder volume; $C_{C}$, fuel chemical composition; OS, oxidation stability.

workflows occurring in the diesel engine. Thus, it is possible to determine which parameters need to be influenced to control any subprocess of the diesel workflow.

Figure 9 presents a proposed algorithm for controlling the supply of fuel when transferring a diesel engine to work on biodiesel. The algorithm is based on the control block diagram presented in this figure and has two stages.

At the first stage, the algorithm controls the mixing process and the fuel oxidation stability. The input parameters at this level are the physicochemical properties of the fuel. In the first step of this stage, the oxidation stability of B100 shall be controlled; the engineers should make sure that appropriate procedures have been applied to maintain the quality and stability of the supplied fuel (using antioxidants or other additives $[45,46])$. At the second step of this stage, the controlled parameter is the quality of the mixture, i.e., the finesse and uniformity of the fuel spray. The algorithm shall control the quality of the mixture with some possible effects. These actions are directly related to the parameters of the gas distribution and fuel supply system. Thus, the engineer shall know (be able to identify) which of these parameters he must act upon to ensure the quality of mixing and fuel supply. At the end of the first stage of the algorithm, it should be noted that there is feedback, so if the selected correcting action does not meet the required quality of the mixture as a result of the CHECK, the selected action is changed accordingly.

After obtaining satisfactory mixing parameters (which shall be specific for each engine), the algorithm proceeds to the second stage.

At the second stage of the algorithm, the power and economic and environmental parameters of the diesel workflow are controlled, taking into account the characteristics of mixture formation in the first place. At this stage, there are also CHECK moves. It should be noted that the second stage is divided into three subprocesses: power management process; economic parameters management process; environmental parameters process. At this stage of the algorithm, the feedback goes to the possible influences involved in the first stage. Thus, the algorithm determines the optimal values of the parameters of the gas distribution system and the fuel supply system. As a result, the optimal characteristics of the mixture of the biodiesel fuel in diesel and the optimal power and economic and environmental characteristics of diesel are obtained. 


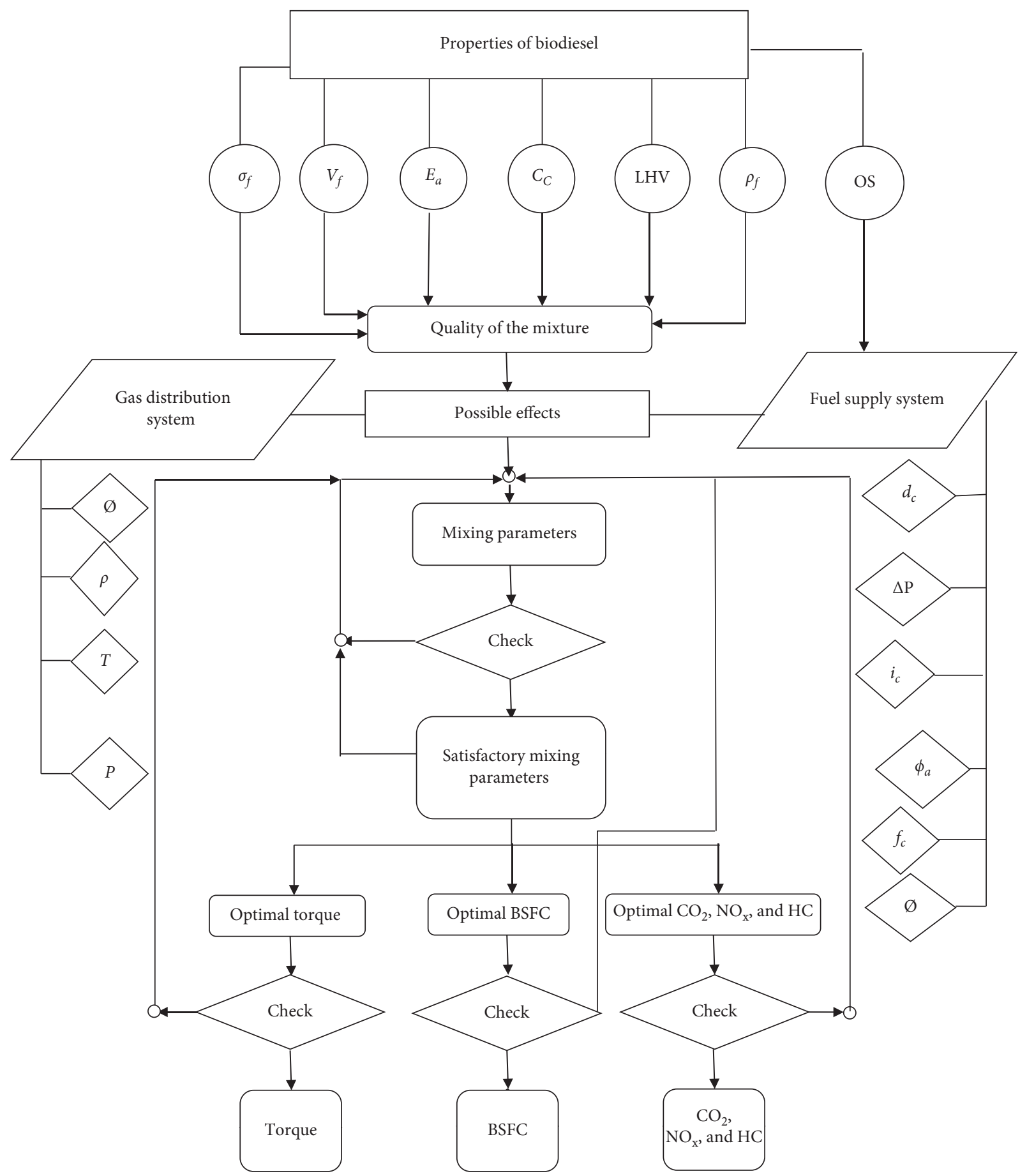

FIGURE 9: Fuel supply control algorithm for biodiesel.

\section{Conclusion}

In this work, it was proposed to investigate the comparative influence of the rate of injection in diesel engines for $100 \%$ biodiesel (B100) and diesel fuel. From that comparison, a methodology and control algorithm was provided for the complete shift to B100 in diesel engines. Rates of injection (ROI) for the two fuels were generated through an experiment-based tool at different injection pressures. From the generated ROI, a two-zone injection model has permitted to determine the disparity between fuel jet atomization and dispersion for the two fuels. It was observed that B100 generated a longer liquid penetration, a higher amount of injected fuel, a wider cone angle, and a coarser spray jet. It was also observed that with higher injection pressure, the above parameters tend to reduce for biodiesel fuel.

Based on the experimental and simulation results, a methodology for fuel jet control was provided as well as an 
algorithm for engine control when the shift to B100 is performed. The methodology proposed in the form of a block diagram presents all possible interactions that could influence fuel jet and mixing parameters in diesel engines, thus helping designers in decision making.

The control algorithm gives the conditions and possible decisions that the designer or the engine control unit could perform when the engine is shifted to B100. The proposed algorithm gives a hierarchical step-by-step correcting procedure that should be followed by the designer or the engine control unit while taking into account the possible degradation that could occur from the use of B100 in diesel engines.

$\begin{array}{ll}\text { Abbreviations } \\ \text { B100: } & \text { 100\% biodiesel fuel } \\ \text { BSFC: } & \text { Break specific fuel consumption } \\ \text { CAD: } & \text { Crank angle degree } \\ \text { CFD: } & \text { Computational fluid dynamics } \\ \text { CN: } & \text { Cetane number } \\ \text { EOI: } & \text { End of injection } \\ \text { EGR: } & \text { Exhaust gas recirculation } \\ \text { HSDI: } & \text { High-speed diesel engines } \\ \text { IMEPg: } & \text { Indicative mean effective pressure } \\ \text { LHV: } & \text { Lower heating value } \\ \text { MFB50: } & 50 \% \text { burnt fuel crank angle } \\ \text { ROI: } & \text { Rate of injection } \\ \text { OS: } & \text { Oxidation stability } \\ \text { TDC: } & \text { Top dead center. }\end{array}$

\section{Data Availability}

The numerical data used to support the findings of this study are available from the corresponding author upon request.

\section{Conflicts of Interest}

The authors declare that they have no conflicts of interest.

\section{References}

[1] M. Matbouei, D. P. Weston, X. Liang, and S. V. Hainsworth, "An investigation of the effect of temperature on the oxidation processes of metallic diesel engine fuel system materials and B100 biodiesel from used cooking oil in exposure testing," Fuel, vol. 285, Article ID 119063, 2021.

[2] A. K. Agarwal and D. Agarwal, "Field-Testing of biodiesel (B100) and diesel-fueled vehicles: Part 2-lubricating oil condition monitoring," Journal of Energy Resources Technology, vol. 143, no. 4, 2020.

[3] A. K. Agarwal and D. Agarwal, "Field-Testing of biodiesel (B100) and diesel-fueled vehicles: Part 1-no load and highway driving emissions, and acceleration characteristics," Journal of Energy Resources Technology, vol. 143, no. 4, 2020.

[4] P. Nautiyal, K. A. Subramanian, M. G. Dastidar, and A. Kumar, "Experimental assessment of performance, combustion and emissions of a compression ignition engine fuelled with Spirulina platensis biodiesel," Energy, vol. 193, Article ID 116861, 2020.
[5] F. Meskéoulé Vondou, C. V. Ngayihi Abbe, J. Tégawendé Zaida, P. Onguene Mvogo, and R. Mouangue, "Experimental study on fire behaviour in room following the disposition of openings," Journal of Combustion, vol. 2020, Article ID 9385712, 11 pages, 2020.

[6] M. N. Nabi, M. S. Akhter, and M. M. Zaglul Shahadat, "Improvement of engine emissions with conventional diesel fuel and diesel-biodiesel blends," Bioresource Technology, vol. 97, no. 3, pp. 372-378, 2006.

[7] C. Song, "An overview of new approaches to deep desulfurization for ultra-clean gasoline, diesel fuel and jet fuel," Catalysis Today, vol. 86, no. 1-4, pp. 211-263, 2003.

[8] P. M. Günter, C. Schwarz, and R. Teichmann, Combustion Engines Development: Mixture Formation, Combustion, Emissions and Simulation, Springer, Londre, Angleterre, 2012.

[9] F. Dos Santos and L. Le Moyne, "Spray atomization models in engine applications, from correlations to direct numerical simulations," Oil \& Gas Science and Technology - Revue D'IFP Energies Nouvelles, vol. 66, no. 5, pp. 801-822, 2011.

[10] Y. Shi, H. W. Ge, and R. D. Reitz, Computational Optimization of Internal Combustion Engines, Springer, Londre, Angleterre, 2011.

[11] M.-H. Yuan, Y.-H. Chen, J.-H. Chen, and Y.-M. Luo, "Dependence of cold filter plugging point on saturated fatty acid profile of biodiesel blends derived from different feedstocks," Fuel, vol. 195, pp. 59-68, 2017.

[12] M. Lapuerta, J. Rodríguez-Fernández, D. FernándezRodríguez, and R. Patiño-Camino, "Cold flow and filterability properties of n-butanol and ethanol blends with diesel and biodiesel fuels," Fuel, vol. 224, pp. 552-559, 2018.

[13] F. Abramchuk, A. Marchenko, N. Razlejtsev, and E. Tretiak, Modern Diesel Engines: Increase of Fuel Economy and Durability, Technika, Kiev, Ukraine, 1992.

[14] A. Kuleshov, "Use of multi-zone DI diesel spray combustion model for simulation and optimization of performance and emissions of engines with multiple injection," SAE, vol. 148, 2006.

[15] И. В. Астачов, В. И. Трусов, А. С. Чачиян, and Л. Н. Голубков, Шодача и расШыливание тоШлива в дизеляч, Машиностроение, Prague, Russia, 1971.

[16] H. Hiroyasu, T. Kadota, and M. Arai, "Development and use of a spray combustion modeling to predict diesel engine efficiency and pollutant emissions: Part 1 combustion modeling," Bulletin of JSME, vol. 26, no. 214, pp. 569-575, 1983.

[17] S. Rajkumar and J. Thangaraja, "Effect of biodiesel, biodiesel binary blends, hydrogenated biodiesel and injection parameters on NOx and soot emissions in a turbocharged diesel engine," Fuel, vol. 240, pp. 101-118, 2019.

[18] C. Zhan, Z. Feng, W. a. Ma, M. Zhang, C. Tang, and Z. Huang, "Experimental investigation on effect of ethanol and di-ethyl ether addition on the spray characteristics of diesel/biodiesel blends under high injection pressure," Fuel, vol. 218, pp. 1-11, 2018.

[19] M. A. Hassani, A. Elkaie, and M. Shafaee, "Numerical investigation of the full-cone spray structure and characteristics provided by a jet-swirl atomizer," Proceedings of the Institution of Mechanical Engineers, Part G: Journal of Aerospace Engineering, vol. 233, no. 15, pp. 5788-5800, 2019.

[20] C. Huang and A. Lipatnikov, "Modelling of gasoline and ethanol hollow-cone sprays using openfoam," in Proceedings of the SAE Technical Papers, Detroit, MI, USA, August 2011.

[21] G. Stiesch, Modeling Engine Spray and Combustion Processes, Springer Science \& Business Media, Berlin, Germany, 2003. 
[22] M. P. B. Musculus and K. Kattke, "Entrainment waves in diesel jets," SAE International Journal of Engines, vol. 2, no. 1, pp. 1170-1193, 2009.

[23] G. E. Cossali, G. Brunello, and A. Coghe, "LDV characterization of air entrainment in transient diesel sprays," $S A E$ Transactions, pp. 162-174, 1991.

[24] В. А. Личанов and А. В. Фоминыч, "Исследование рабочеГо Шроцесса дизеля 2 ч 10, 5/12, 0 Шри работе на метаноле и метиловом эфире раШсовоГо масла с двойной системой тоШливоШодачи, “ 2016.

[25] H. M. Ismail, H. K. Ng, X. Cheng, S. Gan, T. Lucchini, and G. D'Errico, "Development of thermophysical and transport properties for the CFD simulations of in-cylinder biodiesel spray combustion," Energy \& Fuels, vol. 26, no. 8, pp. 4857-4870, 2012.

[26] A. Kuleshov and K. Mahkamov, "Multi-zone diesel fuel spray combustion model for the simulation of a diesel engine running on biofuel," Proceedings of the Institution of Mechanical Engineers, Part A: Journal of Power and Energy, vol. 222, no. 3, pp. 309-321, 2008.

[27] A. L. Kastengren, F. Z. Tilocco, C. F. Powell et al., "Engine combustion network (ECN): measurements of nozzle geometry and hydraulic behavior," Atomization and Sprays, vol. 22, no. 12, pp. 1011-1052, 2012.

[28] A. Kastengren, F. Tilocco, D. Duke, C. Powell, S. Moon, and $\mathrm{X}$. Zhang, "Time-resolved X-Ray radiography of diesel injectors from the engine combustion network," ICLASS Paper, vol. 1369, 2012.

[29] R. Payri, F. J. Salvador, J. Gimeno, and G. Bracho, “A new methodology for correcting the signal cumulative phenomenon ON injection rate measurements," Experimental Techniques, vol. 32, no. 1, pp. 46-49, 2008.

[30] R. Payri, J. Gimeno, J. Cuisano, and J. Arco, "Hydraulic characterization of diesel engine single-hole injectors," Fuel, vol. 180, pp. 357-366, 2016.

[31] R. Payri, J. P. Viera, V. Gopalakrishnan, and P. G. Szymkowicz, "The effect of nozzle geometry over internal flow and spray formation for three different fuels," Fuel, vol. 183, pp. 20-33, 2016.

[32] L. M. Pickett, J. Manin, r. payri, m. bardi, and j. gimeno, "transient Rate of Injection Effects on Spray Development," SAE Technical Papers, vol. 6, 2013.

[33] J. M. Desantes, R. Payri, A. Garcia, and J. Manin, "Experimental study of biodiesel blends' effects on diesel injection processes," Energy \& Fuels, vol. 23, no. 6, pp. 3227-3235, 2009.

[34] C. Park and S. Busch, "The influence of pilot injection on high-temperature ignition processes and early flame structure in a high-speed direct injection diesel engine," International Journal of Engine Research, vol. 19, no. 6, pp. 668-681, 2018.

[35] S. Busch, K. Zha, and P. C. Miles, "Investigations of closely coupled pilot and main injections as a means to reduce combustion noise in a small-bore direct injection Diesel engine," International Journal of Engine Research, vol. 16, no. 1, pp. 13-22, 2015.

[36] S. Busch and P. C. Miles, "Parametric study of injection rates with solenoid injectors in an injection quantity and rate measuring device," Journal of Engineering for Gas Turbines and Power, vol. 137, no. 10, Article ID 101503, 2015.

[37] C. V. Ngayihi Abbe, R. Danwe, and R. Nzengwa, "Comparative numerical study of four biodiesel surrogates for application on diesel 0D phenomenological modeling," Journal of Combustion, vol. 2016, Article ID 3714913, 11 pages, 2016.

[38] A. S. Kuleshov, "Multi-zone DI diesel spray combustion model for thermodynamic simulation of engine with PCCI and high EGR level," SAE International Journal of Engines, vol. 2, no. 1, pp. 1811-1834, 2009.

[39] S. A. Miers, A. L. Kastengren, E. M. El-Hannouny, and D. E. Longman, "An experimental investigation of biodiesel injection characteristics using a light-duty diesel injector," in Proceedings of the Internal Combustion Engine Division Fall Technical Conference, vol. 48116, pp. 311-319, Charleston, SC, USA, October 2007.

[40] S. Som, D. E. Longman, A. I. Ramírez, and S. K. Aggarwal, "A comparison of injector flow and spray characteristics of biodiesel with petrodiesel," Fuel, vol. 89, no. 12, pp. 4014-4024, 2010.

[41] M. Das, M. Sarkar, A. Datta, and A. K. Santra, "Study on viscosity and surface tension properties of biodiesel-diesel blends and their effects on spray parameters for CI engines," Fuel, vol. 220, pp. 769-779, 2018.

[42] H. K. Suh and C. S. Lee, "A review on atomization and exhaust emissions of a biodiesel-fueled compression ignition engine," Renewable and Sustainable Energy Reviews, vol. 58, pp. 1601-1620, 2016.

[43] A. R. Andsaler, A. Khalid, N. S. Adila Abdullah, A. Sapit, and N. Jaat, "The effect of nozzle diameter, injection pressure and ambient temperature on spray characteristics in diesel engine," Journal of Physics: Conference Series, vol. 822, Article ID 012039, 2017.

[44] M. A. Ismael, M. R. Heikal, A. R. A. Aziz, F. Syah, E. Z. Zainal, and C. Crua, "The effect of fuel injection equipment on the dispersed phase of water-in-diesel emulsions," Applied Energy, vol. 222, pp. 762-771, 2018.

[45] Z. Yaakob, B. N. Narayanan, S. Padikkaparambil, S. Unni, and M. Akbar, "A review on the oxidation stability of biodiesel," Renewable and Sustainable Energy Reviews, vol. 35, pp. 136-153, 2014.

[46] J. Pullen and K. Saeed, "An overview of biodiesel oxidation stability," Renewable and Sustainable Energy Reviews, vol. 16, no. 8, pp. 5924-5950, 2012. 